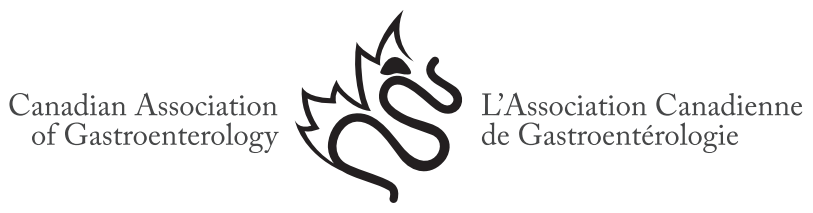

\title{
Canadian Association of Gastroenterology Funding Opportunities
}

\begin{abstract}
CAG/CIHR Industry Research Program
The CAG/CIHR/Industry Research Competition continues to be a very successful and highly sought after funding avenue. To date, more than 250 researchers have been supported via this collaborative Program. This amounts to more than $\$ 21$ million worth of the highest quality research in the field of Gastroenterology in Canada. Many of the researchers supported via this program have been appointed in clinical and/or academic institutions within Canada and have secured competitive independent research funding from the CIHR and other agencies. The following funding opportunities are currently available:
\end{abstract}

Fellowships: Inflammatory Bowel Disease (IBD) - Fall 2015 Priority Announcement

AbbVie-CIHR-CAG IBD Fellowship > two-year term

Crohn's \& Colitis Canada-CIHR-CAG IBD Fellowships > two-year term

Application Deadline: November 2nd, 2015

Fellowships: Gastroenterology (non-IBD) - Fall 2015 Priority Announcement

Allergan-CIHR-CAG Motility Fellowship > two-year term

CIHR-CAG Fellowships > two-year term

Application Deadline: November 2nd, 2015

New Investigator Salary Award: Inflammatory Bowel Disease (IBD) - Winter 2015 Priority Announcement

Crohn's \& Colitis Canada-CIHR-CAG New Investigator Salary Award > five-year term

Application Deadline: December 1st, 2015

How to Apply: Visit http://www.cag-acg.org/cagcihrindustry-research-competition

\section{Resident Research Awards}

The CAG, in partnership with Shire Pharma Canada ULC, Ferring Pharmaceuticals and Allergan Canada, is pleased to announce the availability of five (Shire-2, Ferring-2, Allergan-1) Resident Research Awards. These awards are designed to encourage research during clinical training and provide a foundation for research activities after gastroenterology training has been completed. The long-term goal is to stimulate research interests (basic science or clinical) in gastroenterology residents and also promote full-time faculty involvement in the research training of residents. The value of the award is $\$ 5,000$. The award is to support the research project and is not a stipend.

How to Apply: Visit http://www.cag-acg.org/resident-research-awards

Application Deadline: January 31st, 2016

\section{PhD Scholarships}

The CAG is pleased to announce the availability of three PhD scholarships for research in gastroenterology. These scholarships are designed to provide a two-year financial support for $\mathrm{PhD}$ candidates that will be enrolled in a $\mathrm{PhD}$ graduate program at a Canadian institution.

Application Deadline: December 1st, 2015

How to Apply: Visit http://www.cag-acg.org/phd-scholarships

The CAG is proud to acknowledge its Benefactor Corporate Sponsors:

AbbVie Corporation Allergan Canada Janssen Inc

Olympus Canada Inc

Pentax Canada Inc

Takeda Canada Inc 


\section{Summer Studentships}

The CAG is pleased to make available a total of seventeen 2016 Summer Student Scholarships for research in Gastroenterology.

These scholarships arise from the CAG (8), Crohn's \& Colitis Canada (6), the Alberta Association of Gastroenterology (ASG)/CAG (2), and the CAG and Canadian Digestive Health Foundation with the Ivan Beck Memorial Summer Studentship Award (1). These scholarships are designed to provide short-term financial support for undergraduates who wish to obtain introductory training in research in the field of Gastroenterology. The ASG-CAG awards will be offered to the top two scored Alberta applicants following the determination of the Ivan Beck Award.

How to Apply: Visit http://www.cag-acg.org/summer-studentships

Application Deadline: January 31st, 2016

\section{Research Conference Grant}

The intent of this program is to provide a grant of up to $\$ 10,000$. The grant is meant to support organizers to fund a conference in Canada which is expected to benefit CAG members and trainees (basic and/or clinical). Conferences are intended to be larger meetings of more than 50 participants and to be no more than one or two days in duration and to incorporate both local and international faculty. The grant can be used to offset costs incurred by allowing trainees and participants to attend the meeting (e.g. registration, travel, accommodation and meals) but not for payment of honoraria. One conference grant will be supported in any one 12-month period between July 1st and June 30th.

How to Apply: Visit http://www.cag-acg.org/cag-research-conference-grant

Application Deadline: September 1st, 2015

\section{Research Workshop Grant}

The intent of this program is to provide a grant of up to $\$ 5,000$. The grant is meant to support organizers fund a conference/workshop which is expected to benefit CAG members and trainees (basic and/or clinical). The grant can be used to offset costs incurred by allowing trainees to attend the meeting (e.g. registration, travel, accommodation and meals) but not used for payment of honorarium. A maximum of 2 workshops will be supported in any one 12-month period between July 1st and June 30th.

How to Apply: Visit http://www.cag-acg.org/workshop-grant

Application Deadline: September 1st, 2015

\section{Community Research Grant (CREG)}

The CAG and the Canadian Digestive Health Foundation are pleased to present an award specifically designed to assist clinically-based gastroenterologists, who are members of the CAG, take advantage of special educational and professional skills upgrading opportunities. Applicants must be CAG members, in practice for at least one year at the time of application, and may not have received this award previously (this is a one-time award).

How to Apply: Visit http://www.cag-acg.org/community-research-grant-creg

Letter of Intent (LOI) Deadline: October 15th, 2015

Application (if LOI approved) Deadline: December 15th, 2015

\section{Education Research Grant}

The CAG strongly supports the development and maintenance of the formal educational research component within Gastroenterology in Canada. The CAG, with our partner, AbbVie Centre of Excellence in Continuing Health Education, is pleased to offer a new education research grant aimed to foster quality research in medical education (which could include aspects of professional collaboration), as well as maintain, and grow this important role within Canadian Gastroenterology.

How to Apply: Visit http://www.cag-acg.org/cag-education-research-grant

Application Deadline: September 15th, 2015 


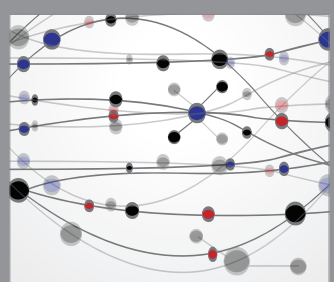

The Scientific World Journal
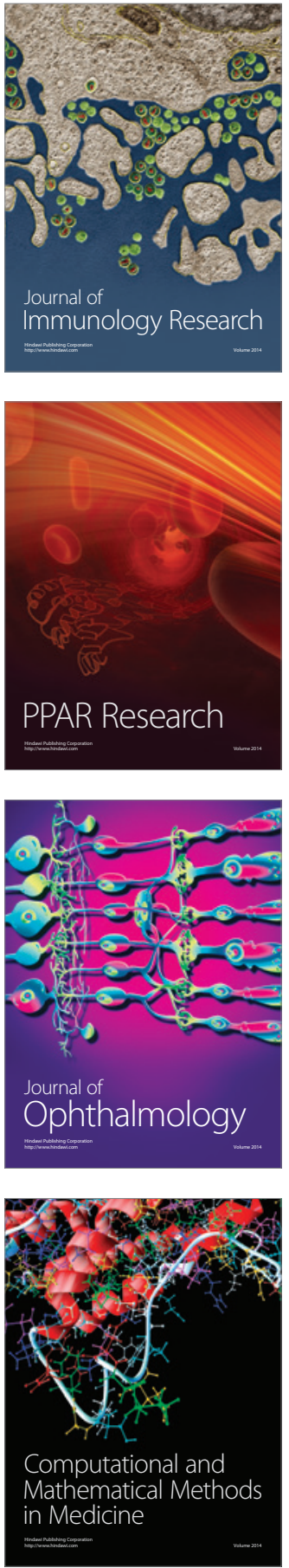

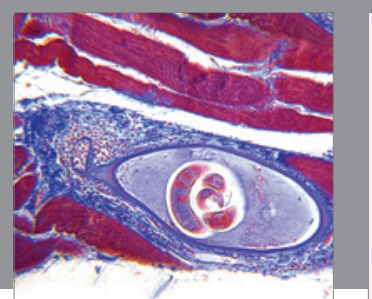

Gastroenterology Research and Practice

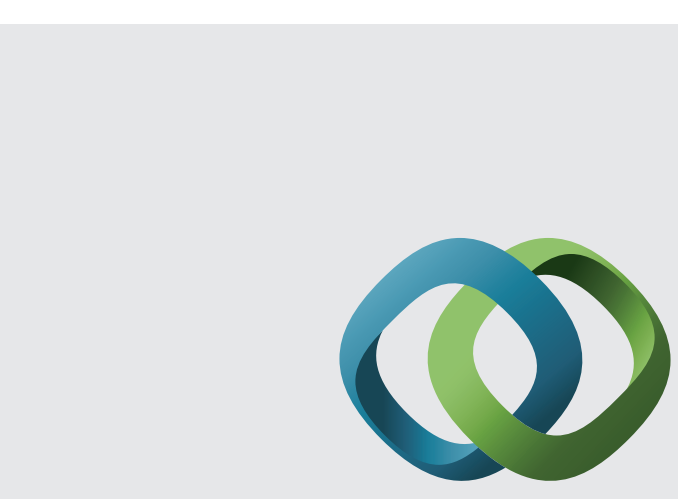

\section{Hindawi}

Submit your manuscripts at

http://www.hindawi.com
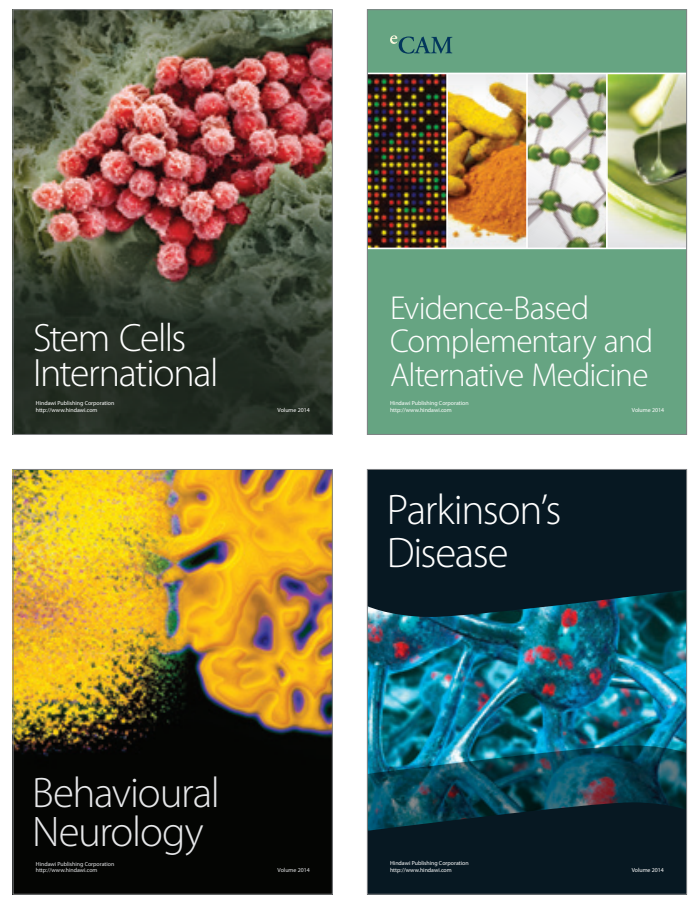
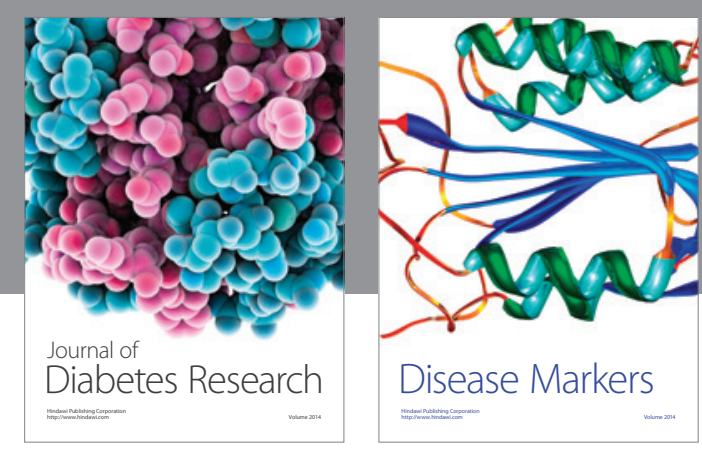

Disease Markers
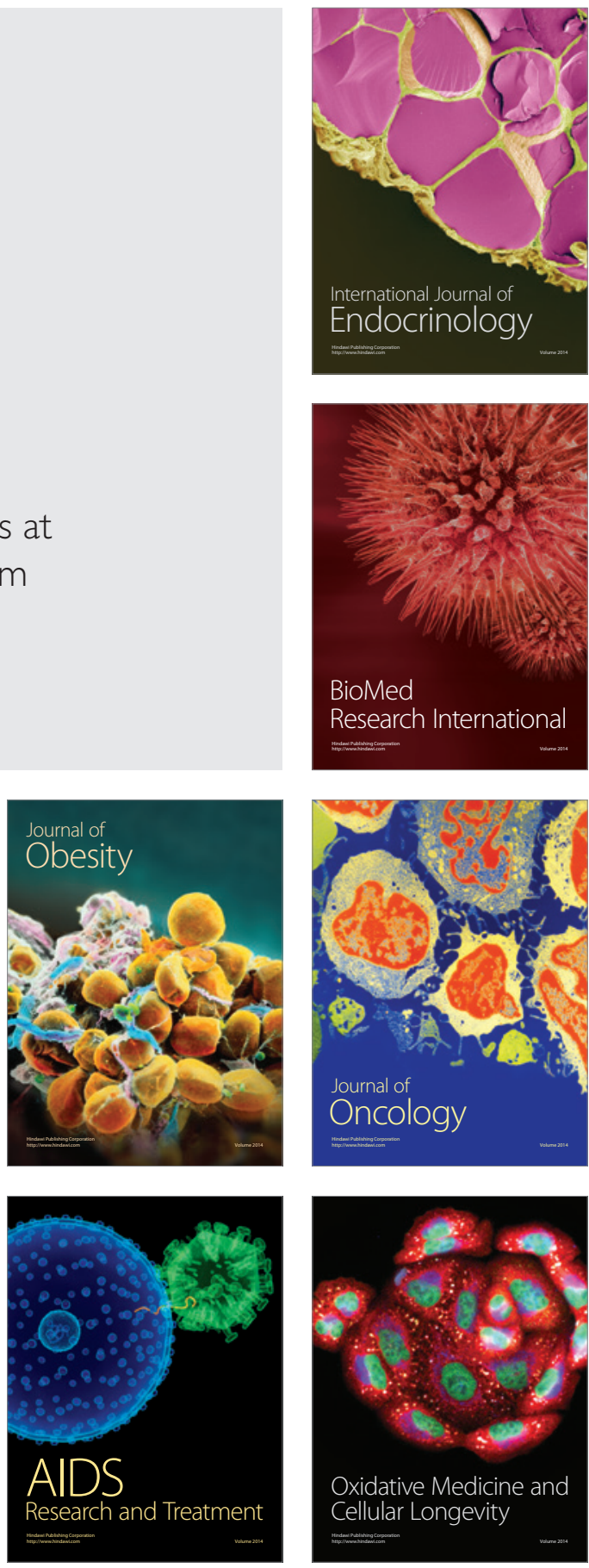